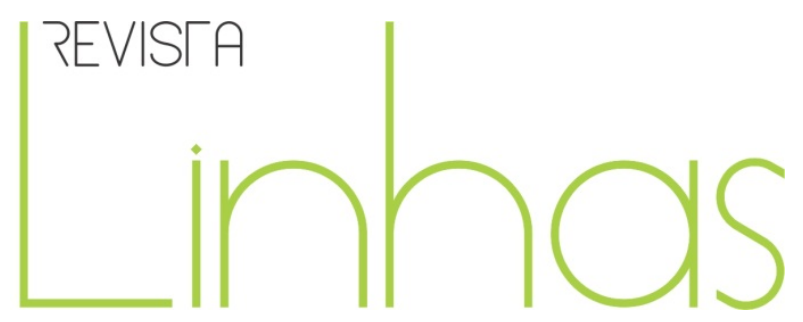

\title{
O novo público do ensino superior brasileiro e a tradição acadêmica: o caso das humanidades na UNIFESP (Universidade Federal de São Paulo)
}

\begin{abstract}
Resumo
A análise dos estudantes franceses e da universidade realizada por Bourdieu e Passeron em Os Herdeiros constitui um modelo sugestivo para pensar a atual universidade brasileira, porque põe em relação elementos institucionais e culturais, tais como os modos de relação pedagógica e as experiências de pertencimento ao ambiente universitário. Para compreender como essas relações se configuram um ambiente que pretende, simultaneamente, herdar tradições e ampliar o acesso das camadas populares, vale a pena considerar, tal como em Os Herdeiros, as relações entre a legitimidade da instituição e dos cursos no campo acadêmico, as particularidades da cultura da universidade e os modos de relação com o saber que esta propõe enquanto oferece formação profissional. Toma-se aqui o caso do campus de humanidades da Universidade Federal de São Paulo, fundado em 2007 como parte da expansão universitária da última década, direcionado para a formação de bacharéis e professores em humanidades. Este campus acolheu estudantes com um perfil majoritariamente popular, cujo perfil social e demográfico dificulta a vivência naturalizada da universidade. A tensão entre o ideal meritocrático da universidade e as políticas de permanência e de ampliação do acesso culminou em 2012, quando as precárias condições estruturais puseram em jogo as representações contraditórias da universidade - particularmente os docentes dos cursos mais legítimos, portadores de um ideéia tradicional de universidade e os estudantes mais combativos, que defendiam a "universidade popular".
\end{abstract}

Palavras-chave: Ensino superior; Sociologia da educação; Democratização.

\section{Para citar este artigo:}

LUGLI, Rosario Silvana Genta. O novo público do ensino superior brasileiro e a tradição acadêmica: o caso das humanidades na UNIFESP (Universidade Federal de São Paulo). Revista Linhas. Florianópolis, v. 15, n. 29, p. 297-316, jul./dez. 2014.

DOI: $10.5965 / 1984723815292014297$

http://dx.doi.org/10.5965/1984723815292014297 


\title{
The new students of Brazilian higher education and the academic tradition: the case of Humanities in the Federal University of São Paulo
}

\begin{abstract}
Bourdieu e Passeron's analysis of the French alumni and University in the book The Inheritors constitutes a significant model to think Brazilian University nowadays, because it articulates institutional and cultural elements, as teaching styles and relationships and the different experiences of the university environment. To understand how these elements are combined in an institution that intends simultaneously to inherit traditions and open itself to a larger part of the population it is important to consider, as in The Inheritors, the relation among several factors: the legitimacy of the institution and of the courses in the academic field, the specificities of the university culture and how the knowledge is presented as the professional education is given. It is presented the case of the humanities campus of the Federal University of São Paulo, founded in 2007 as part of the university expansion of the last decade, which main objective was the preparation of teachers and bachelors in social sciences, philosophy, education and history. This campus received students who were mostly from the working class, whose social and demographic profile made it difficult to experience the academic environment and its demands as natural. The tension between the meritocratic ideal of the university and the democratization policies combined with the poor structural conditions resulted in a severe crisis in 2012, when contradictory representations of the role of the university emerged - polarized between the professors of the most legitimate courses, carriers of a traditional idea of the university and the most combative students, who defended the "popular university".
\end{abstract}

Keywords: Higher education; Sociology of education, National university. 


\section{Introdução}

A leitura de Os Herdeiros é bastante sugestiva para a compreensão do ensino superior público no Brasil tal como vem se configurando há alguns anos. Num primeiro olhar, a identificação dos modos pelos quais as desigualdades sociais se traduzem em desigualdades educacionais é bastante perceptível ao tomar os dados socioeconômicos dos alunos e sua distribuição pelos cursos na hierarquia universitária. Zago (2007) demonstra que a ampliação do acesso dos estudantes de camadas populares tem se dado nos cursos menos prestigiosos e a sua permanência é bastante influenciada pelas condições econômicas. Essa compreensão do "elitismo" presente no ensino superior tem sido combatida no sistema de ensino federal por políticas públicas que ampliaram a disponibilidade de auxílios (moradia, alimentação, transporte, creche). No entanto, há uma dimensão cultural que Os Herdeiros analisa com relação à universidade francesa, relativa aos mecanismos de perpetuação da injustiça no interior da própria relação de ensino. Analogamente ao que ocorre na escola comum, o tratamento igual a pessoas que são, pela origem, desiguais em termos das possibilidades de fazer frente ao que a instituição demanda como natural, está firmemente estabelecido na própria relação pedagógica a que os sujeitos se submetem na universidade. A análise, quando passa a contrapor o "tipo ideal" do estudante e os modos concretos da ação dos alunos na universidade, identifica elementos que são típicos da cultura universitária francesa e que parecem ser também os nossos, ao menos na área das ciências humanas. Particularmente no caso da Unifesp ${ }^{1}$, do qual se pretende analisar um aspecto, seu campus de ciências humanas tem como modelo e contraponto a Universidade de São Paulo, cuja história tem uma forte inspiração no modelo francês. Por essa via, alguns dos traços culturais descritos nesse trabalho são muito similares, apesar da distância no tempo e das particularidades geográficas.

De um modo muito amplo, pretende-se aqui tratar do que tem significado o choque entre a ideologia meritocrática da Universidade e o acesso ampliado de estudantes das camadas populares que se verifica em razão das políticas de Estado. Este

\footnotetext{
${ }^{1}$ Unifesp - Universidade Federal de São Paulo.
} 
choque foi particularmente agudo no campus de humanidades da Unifesp, situado na periferia da cidade de Guarulhos, que é parte da região metropolitana de São Paulo. Somaram-se às contradições internas da própria universidade a precariedade das instalações, que, superlotadas, obrigavam os alunos a estudarem nos lugares mais insólitos (debaixo das escadas, por exemplo), dificultavam os eventos que constituem a "vida universitária" e, finalmente, dificultavam as atividades de pesquisa dos professores, que só podiam contar a muito custo com as contrapartidas institucionais necessárias para a obtenção de financiamentos de pesquisa. No ano de 2012, as tensões eclodiram numa greve de alunos que durou cinco meses (23/03 a 23/08/2012), durante a qual também houve um mês de greve de professores. Vale ressaltar que foi ano eleitoral, o que potencializou o uso político do conflito, entre os inúmeros significados que os acontecimentos adquiriram nos discursos dos diversos grupos de agentes. Trata-se de um período que impactou fortemente a vida institucional e do qual, até o momento (2014), ainda sentimos os efeitos. Por essa razão, não se pretende aqui analisar amplamente o movimento dos alunos e professores, suas causas ou seus méritos políticos. Trata-se de identificar nessa situação de crise, com uma inspiração bastante livre no texto de Os Herdeiros, a emergência de discursos e comportamentos de alunos e sobre os alunos que podem contribuir para a compreensão dos mecanismos sociais em ação nas próprias relações pedagógicas que se instituíram ali, como caso exemplar no conjunto das universidades federais do processo de expansão.

\section{O projeto acadêmico do campus Guarulhos}

A Universidade Federal de São Paulo era especializada em cursos da área médica² e, no quadro das políticas de expansão universitária que o governo federal implementou a partir de 2006, com o Programa Expandir da Secretaria de Educação Superior do MEC 3 , criou novos campi, em diversas áreas do conhecimento. Guarulhos estava entre eles. Concebido como o local que concentraria os cursos de ciências humanas da instituição, iniciou com os cursos de Filosofia, Ciências Sociais, História e Pedagogia. Em 2009, os

\footnotetext{
${ }^{2}$ Medicina, Enfermagem, Fonoaudiologia e Ciências Biológicas modalidade médica.

${ }^{3}$ MEC - Ministério da Educação.
} 
cursos de História da Arte e Letras receberam suas primeiras turmas.

Por meio de convênio com a Prefeitura de Guarulhos, o campus universitário foi localizado no Bairro dos Pimentas, na periferia da cidade, com a intenção de que sua presença pudesse trazer melhorias para o entorno, particularmente em termos de projetos culturais. Tal como é característico das regiões de periferia metropolitana, o bairro não possui infraestrutura de lazer, saúde ou transporte adequadas para a sua população. O edifício no qual o campus foi instalado existia previamente como sede vazia de uma escola técnica e em seu terreno foi construído um teatro que serviria tanto à universidade como à comunidade ao redor. Em 2012, seis anos depois do início das atividades, o edifício projetado especificamente para o campus ainda não tinha sido construído devido a dificuldades diversas, que iam da legislação federal ao mercado de construções de grande porte - a superlotação dos ambientes e a inadequação da estrutura para os usos a que se destinaram se faziam sentir cotidianamente ${ }^{4}$ Esses fatores foram, manifestamente, o estopim da crise. A queixa mais visível dos alunos do campus Guarulhos dizia respeito às dificuldades de acesso ao campus - o único transporte público que chega à região são os ônibus que atendem o bairro e que recebiam o fluxo de alunos nos horários de entrada e saída. O impacto mais severo disso era a enorme dificuldade de boa parte dos alunos de cumprir com os horários de início e de término das aulas: a distância, os congestionamentos e o horário de circulação do transporte público constituíam impedimentos significativos. Além disso, quase 60\% dos ingressantes em 2011 não residiam em Guarulhos ${ }^{5}$, o que indica custos consideráveis de transporte, tendo em vista a tarifa intermunicipal.

O projeto pedagógico inicial do campus de humanidades previa disciplinas obrigatórias de filosofia para os primeiros anos de todos os cursos - concebidas não como uma introdução à filosofia, mas como experiências de leitura filosófica a serem realizadas

\footnotetext{
${ }^{4}$ Esta situação não foi exclusiva do campus Guarulhos da Unifesp, tendo sido registrada pelos meios de comunicação para os demais campi da própria instituição e para muitas outras universidades federais criadas a partir de 2006

${ }^{5}$ Este dado foi obtido somando-se os estudantes cujas famílias residem em São Paulo (48\%) e no interior do estado (10,73\%), mas deve-se considerar que há $35,97 \%$ de estudantes que residem na Grande São Paulo, sem que o dado especifique quantos são da própria cidade de Guarulhos. A imprecisão dos dados permite apenas assinalar a tendência - a maior parte dos estudantes do campus Guarulhos não é oriunda da própria cidade.
} 
a partir da especialidade de cada professor. Isso significou que alunos recém-chegados à universidade eram mesclados em salas nas quais conviviam alunos de todos os cursos e realizavam leituras filosóficas de alto nível, uma vez por semana, durante dois semestres. Além disso, durante os cursos, os alunos fariam um semestre de inglês e outro de francês instrumental, o que teoricamente favoreceria a leitura de autores em seus idiomas originais. Finalmente, foi previsto para os alunos a obrigatoriedade de cursarem um certo número de disciplinas fora de seus cursos de origem. Esses mecanismos visavam garantir o rigor de pensamento, uma sólida cultura geral e uma vivência ampla da riqueza cultural da universidade, ou seja, a explícita valorização dos elementos mais desvinculados da função instrumental do ensino superior, relativa à formação profissional.

Esse projeto, herança dos valores tradicionais em nossas universidades, orientou a contratação de professores aptos a conduzi-lo: a maioria dos docentes realizou seus doutorados em universidades públicas: atualmente, de um total de 231 docentes, 186 vêm de universidades federais e das estaduais paulistas - dentre estes últimos, 134 são doutores pela Universidade de São Paulo. Os docentes restantes obtiveram doutorado em universidades confessionais (como a $\mathrm{PUC}^{6}$, que é o caso de 23 docentes) ou em instituições da Europa e Estados Unidos. O sentido do projeto, visto em conjunto com a origem institucional dos docentes, permite dizer, tomando de empréstimo a análise d'Os Herdeiros, que este grupo, mesmo que não possua, à primeira vista, coesão interna (tendo em vista os agrupamentos por curso, por tendência política ou teórica), tem em comum uma concepção da universidade e dos seus valores. Isso é garantido pelo longo processo de formação, no sentido de que seus currículos expressam inserção competitiva em atividades de pesquisa, que é um dos critérios principais para a contratação, e no reconhecimento por seus pares da posse das características distintivas do habitus acadêmico que é, afinal, a aprovação no concurso público. Esse grupo de professores também se caracteriza pela diplomação relativamente recente: apenas 19 deles obtiveram o doutoramento nas décadas de 80 e 90, enquanto que o maior número obteve o doutorado entre 2005 e 2009, ou seja, há menos de dez anos, como se pode ver no quadro a seguir.

\footnotetext{
${ }^{6}$ PUC - Pontifícia Universidade Católica.
} 


\section{Período de obtenção do doutoramento dos professores do campus Guarulhos. ${ }^{7}$}

$\begin{array}{ll}\text { Década de } 1980 & 2 \\ \text { Década de } 1990 & 17 \\ 2000 \text { a } 2004 & 64 \\ 2005 \text { a } 2009 & 96 \\ 2010 \text { a } 2013 & 43\end{array}$

O pouco tempo de carreira sugere reputações e trajetórias ainda em construção, mesmo que já sejam legítimos em suas áreas de origem. Esse fator, em conjunto com o projeto acadêmico do campus, de reafirmação dos valores tradicionais da universidade, e com sua fraca institucionalidade advinda, sobretudo, do seu pouco tempo de existência, leva a uma situação que tende a favorecer ações e percepções “ortodoxas” no campo universitário, como forma de garantir recompensas simbólicas nesse contexto. Sob o rótulo da inovação, instaurou-se um ensino que tem como finalidade retomar os valores tradicionais e fundamentais da instituição universitária entre nós, o que significa, embora isso não seja dito explicitamente, uma forte ideologia meritocrática. No entanto, isso aconteceu no bojo de políticas públicas cuja proposta era fundamentada exatamente no oposto a essa ideologia: o ingresso democratizado e o forte investimento em mecanismos de permanência trouxeram à universidade pública alunos com um perfil diferente do que era usual.

\section{Os estudantes do campus Guarulhos}

Os estudantes que pertenciam ao campus Guarulhos em 2012, seis anos após sua inauguração, já pela via do Sistema de Seleção Unificada (SISU), implementado a partir de 2009, pertencem, majoritariamente, às camadas populares, como indica a pesquisa de caracterização socioeconômica dos estudantes da UNIFESP realizada pela Pró-reitoria de

\footnotetext{
${ }^{7}$ O campus conta ainda com 6 professores que estão em processo de obtenção do doutoramento.
} 
Assuntos Estudantis (PRAE), em 2011 ${ }^{8}$. Essa pesquisa, iniciativa do órgão universitário que administra os auxílios para a permanência, confirmou o campus de Guarulhos como aquele que concentra os cursos que recebem os alunos mais pobres na Unifesp, com $64,2 \%$ de estudantes cujas famílias vivem com até 5 salários mínimos. Não por acaso, é o campus que recebe o maior número de solicitação de auxílios (moradia, alimentação, transporte, creche) na Unifesp.

\section{Porcentagem de alunos por campus e faixa de renda}

\begin{tabular}{|c|c|c|c|c|c|c|c|}
\hline & B. Santista & Diadema & Guarulhos & Osasco & São J. Campos & São Paulo & UNIFESP \\
\hline $\begin{array}{l}\text { Nenhuma } \\
\text { renda }\end{array}$ & 0,0 & 0,0 & 0,5 & 0,4 & 0,5 & 0,0 & 0,2 \\
\hline $\begin{array}{l}\text { Até cinco } \\
\text { salários } \\
\text { mínimos }\end{array}$ & 50,0 & 49,3 & 64,2 & 33,7 & 46,2 & 32,4 & 48,7 \\
\hline $\begin{array}{l}\text { Superior a } \\
\text { cinco salários } \\
\text { mínimos }\end{array}$ & 50,0 & 50,7 & 35,3 & 66,0 & 53,3 & 67,6 & 51,1 \\
\hline Total & 100,0 & 100,0 & 100,0 & 100,0 & 100,0 & 100,0 & 100,0 \\
\hline
\end{tabular}

Guarulhos também é o campus que possui o maior número de alunos com mais de 25 anos - seus estudantes na faixa dos 18 anos estão em porcentagem sensivelmente inferior aos dos demais campi e a relação se inverte significativamente para as faixas etárias entre 22-24, 25-29 anos e é muito maior na faixa de 30 anos ou mais, como se pode ver na tabela ao final do texto. Esse dado, combinado com o fato de que o campus Guarulhos também é o campus com o maior número de estudantes casados, pode indicar o adiamento do projeto de cursar o ensino superior, que é viabilizado pela possibilidade de estudar numa instituição pública.

\footnotetext{
${ }^{8}$ Essa pesquisa foi realizada por meio de questionário que os ingressantes respondiam no momento da matrícula. Embora não fosse obrigatório, obteve-se alto número de respostas válidas: 606, de um total de 698 matrículas para o ano de 2011, ou seja, $87 \%$.
} 
Idade dos alunos em 31 de dezembro de 2009 por campus

\begin{tabular}{llllllll}
\multicolumn{1}{c}{ Idade } & Santos & Diadema & Guarulhos & \multicolumn{1}{c}{ Osasco } & $\begin{array}{c}\text { S. José dos } \\
\text { Campos }\end{array}$ & São Paulo & UNIFESP \\
$\begin{array}{l}16 \text { anos } \\
\text { menos }\end{array}$ & 0,00 & 0,58 & 3,30 & 1,04 & 0,54 & 0,00 & 1,23 \\
17 anos & 18,93 & 18,32 & 16,17 & 19,44 & 26,63 & 13,40 & 17,93 \\
18 anos & 25,00 & 26,90 & 14,03 & 26,74 & 28,26 & 23,36 & 22,67 \\
19 anos & 13,93 & 16,96 & 9,90 & 21,53 & 16,85 & 25,23 & 16,42 \\
20 anos & 9,29 & 9,36 & 7,43 & 7,64 & 6,52 & 14,95 & 9,17 \\
21 anos & 5,00 & 4,09 & 5,61 & 4,51 & 5,43 & 6,23 & 5,11 \\
22 a 24 anos & 7,14 & 8,97 & 13,37 & 9,03 & 4,89 & 9,35 & 9,67 \\
25 a 29 anos & 11,07 & 7,60 & 13,70 & 6,60 & 6,52 & 3,74 & 8,94 \\
30 anos ou & 9,64 & 7,21 & 16,50 & 3,47 & 4,35 & 3,74 & 8,85 \\
mais & & & & & &
\end{tabular}

Fonte: CRUZ e CESPEDES, 2012, p. 33.

Esses elementos indicam dificuldades objetivas para a vivência plena da vida universitária como um período autônomo, encerrado em si mesmo e que "esquece" o seu sentido de preparação para a vivência profissional, ou, conforme a expressão no texto d'Os Herdeiros, a "irrealidade da prática universitária". No entanto, toda a instituição e o habitus de seus professores estão pensados para proporcionar essa vivência. Penso que reside nesse conflito o "mal-estar" relatado por Zago em sua pesquisa com estudantes de origem popular no ensino superior - essa autora o identifica às disparidades sociais. De fato, essa é a causa genérica, mas se converte, no campo universitário, no choque entre expectativas e disposições muito díspares entre si que resulta na identificação desses alunos como inaptos. Uma questão ainda por explorar diz respeito às disposições para a submissão aos valores acadêmicos apresentada por esses alunos mais velhos, com uma identidade adulta já consolidada e com poucas chances de seguir carreira acadêmica, uma vez que a dedicação exclusiva que esta exige lhes é impossível.

Para além do acesso, a experiência no ensino superior não é isenta de sofrimento, incertezas e angústias decorrentes da fragilidade econômica para garantir a sobrevivência e a permanência na universidade. Ela 
apresenta uma série de obstáculos relacionados às condições materiais necessárias para viabilizar necessidades básicas como transporte, livros, vestuário, alimentação, moradia e não é isenta de outros de ordem emocional, subjetiva, em razão de um certo "mal- estar discente" que pode ser traduzido pelo modo como sentem as disparidades sociais com as quais são confrontados no meio universitário. (ZAGO, 2007, p. 147)

\section{As possibilidades da leitura legítima}

Um breve olhar para as condições objetivas da leitura de textos acadêmicos, elemento chave do modo de ensino das humanidades, permite ter um vislumbre dos mecanismos de seleção da instituição universitária e os seus efeitos potenciais em estudantes das camadas populares. Podemos assumir que seja bastante raro que, durante o primeiro ano do curso universitário, alguém já tenha tido contato com textos escritos nos gêneros acadêmicos (artigos, resenhas, teses etc), que possuem uma lógica própria de construção da argumentação. Essa leitura é compreendida, na maior parte das vezes, como algo autoevidente e que, portanto, não precisaria ser ensinado - o que significaria "escolarizar" a universidade, uma vez que os modos próprios da escrita acadêmica são considerados como habilidades que já deveriam ter sido obtidas em níveis anteriores de ensino.

Durante a crise da Unifesp, um grupo de docentes, nos quais se destacavam aqueles vinculados ao curso de Filosofia, redigiu e divulgou amplamente nas instâncias universitárias um "Dossiê para debate", intitulado A crise da Escola de Humanidades da Unifesp e sua permanência nos Pimentas. Nesse documento, que tinha como tese fundamental a necessidade de que o campus Guarulhos fosse deslocado para o centro de São Paulo, de modo a garantir sua qualidade acadêmica, há passagens significativas sobre os alunos e sobre o que se acredita ser o papel da universidade:

Ideal em uma universidade seria poder pressupor que seus estudantes possuem enraizados hábitos culturais e circulação intensa entre os elementos da cultura formal, pois, então, a universidade, sobretudo na 
formação em filosofia e ciências humanas, poderia desenvolver plenamente o caráter crítico de sua reflexão. No Brasil, porém, essa pressuposição mostra-se inteiramente fora de propósito, levando a universidade a ter de estimular seus estudantes a interessar-se por todas as formas de cultura, sobremaneira a cultura erudita, aquela que requer iniciação. Isso quer dizer que os estudantes já revelam elevado grau de exclusão, ainda que, muitas vezes, provenham de classes econômicas privilegiadas. (...)

[o campus Guarulhos] Arrisca-se a tornar-se, com o decorrer dos anos, uma instituição de transmissão mínima de saberes, não logrando ultrapassar os níveis básicos de apresentação dos fundamentos das áreas que a compõem, sem poder desenvolver as potencialidades de sua presença na sociedade; (...)

Todavia, em sua prática atual, a EFLCH [Escola de Filosofia, Letras e Ciências Humanas] impõe a seus estudantes também uma seleção segundo o critério da possibilidade de conviver com as dificuldades de acesso e de despender tempo no transporte. Isso termina por ser um critério prático de seleção e exclusão, sobretudo porque muitos estudantes com melhor preparo para bem acompanhar um curso superior desistem de frequentar a EFLCH, obrigando-a a receber estudantes semialfabetizados, para os quais seria de desejar um processo formativo específico que suprisse suas carências, introduzindoos no mundo da cultura formal e permitindo-lhes encontrar as condições necessárias para futuramente acompanhar uma formação de nível superior. (UNIVERSIDADE, 2012, p. 15)

Central nesses excertos é a apresentação das insuficiências dos alunos recebidos, que "rebaixa" o trabalho de ensino na graduação - e a recusa ao trabalho demorado e elementar que seria necessário para supri-las. Não se trata aqui de dizer o que a universidade deve ou não assumir como tarefa de formação, tendo em vista as notórias deficiências da educação básica entre nós - mas de identificar um foco de tensão considerável na relação pedagógica. E que é, nos termos em que se coloca, insolúvel, porque não pode ser sanado nos 4 anos (tempo mínimo de duração dos cursos em Guarulhos) em que ainda se deve garantir os conhecimentos para a obtenção do diploma.

Quais as condições para a leitura e a produção escrita, que a universidade não pode tomar como natural, mas que percebe como condição para o ensino adequado? Vários elementos da caracterização socioeconômica desses estudantes sugerem a escassez de capital cultural herdado ou mesmo adquirido: apenas $15,84 \%$ dos pais e $17,82 \%$ 
das mães possuem ensino superior completo, havendo cerca de $8 \%$ de estudantes com pais analfabetos ou alfabetizados fora da escolarização regular. 20,46\% dos pais e $17,16 \%$ das mães cursaram apenas as quatro primeiras séries do ensino fundamental. Isso indica que apenas uma minoria desse grupo de alunos teria a possibilidade de conviver com práticas de leitura e escrita mais próximas do acadêmico em suas casas. A esses dados, soma-se que $65,84 \%$ são egressos de escolas públicas, o que tendencialmente indica pouca fluência quanto à leitura, se tomarmos os dados de Batista e Ribeiro (2005), segundo os quais alunos de escolas públicas apresentam médias de desempenho em leitura mais baixas que os de particulares. Finalmente, no que diz respeito ao tempo livre para essa leitura, que por ser pouco fluente é mais vagarosa e tende a se apresentar como menos "crítica" no sentido de que dificilmente transcende a decifração dos argumentos, deve-se assinalar que, entre os estudantes do campus Guarulhos, 39,8\% trabalham, 31,19\% estão sem atividade laboral no momento da pesquisa e apenas $24,09 \%$ apenas dedica-se a estudar (Cruz e Cespedes, 2012, p. 87).

O ideal da leitura predominante nas ciências humanas remete a uma modalidade de relação com os textos acadêmicos que demanda capacidade de compreensão de argumentos complexos, da realização da leitura crítica dos mesmos e da escrita com uso autônomo e crítico dos gêneros textuais específicos da academia (fichamento, resenha, artigo, monografia, por exemplo). Tendo isso em vista, é inegável que o ideal da vivência universitária supõe, sem o dizer, tempo ocioso e lugar adequado (por exemplo, longas horas na biblioteca como local de estudo) para o contato com os textos científicos. Isso se obtém à custa de um ascetismo que parece mais factível para uma juventude ainda solteira e economicamente dependente da família e que não parece muito realista para pessoas já mais velhas e que são responsáveis pela renda familiar (o que significa que têm praticamente o dia todo tomado pelo trabalho). As condições concretas da vivência universitária ideal não são ditas e, por essa razão, se apontam os alunos "semialfabetizados" como “indesejáveis" que não pertencem a esse ambiente.

Uma outra marca dessas dificuldades, assinalada por Bertoluci em artigo de 2009 sobre o tipo de leitura realizada por estudantes universitários com um perfil bastante semelhante ao dos alunos do campus Guarulhos da Unifesp, é a passividade face à leitura 
autorizada do professor - uma situação em que os alunos não apresentam, após a leitura dos textos, condições de questioná-los, concordar ou discordar dos mesmos com argumentos consistentes. Dessa forma, a compreensão dos textos depende fortemente das explicações docentes. Em alguma medida, isso é efeito da escassa familiaridade com o tipo de leitura que se demanda, da falta de condições objetivas e da inexistência de intervenções institucionais que permitam a aquisição de estratégias de leitura. Essa passividade, no entanto, não é somente produto dessas condições, também é parte essencial da manutenção do sistema universitário:

Produto do sistema, o estudante e o professor exprimem essa lógica: o estudante não contribui em nada para orientar a "produção" ou a transmissão do saber; o professor não consulta (ou muito pouco) o estudante sobre suas necessidades, e, quando tenta fazê-lo, normalmente encontra a passividade ou o espanto do estudante que, animado por uma propensão indiferenciada a absorver saber, espera precisamente do professor que ele indique as urgências e escolha por si mesmo satisfazer as necessidades que criou decidindo satisfazê-las. 0 professor tem portanto a iniciativa em tudo; cabe a ele definir os programas, os assuntos dos cursos, dos trabalhos, das leituras, assim como a quantidade de fantasia que pode ser injetada sem risco na máquina escolar. (Bourdieu; Passeron, 2014, p.62)

A parcela dos estudantes que não têm tempo livre para ler ou para participar da vida universitária, nem capital cultural, nem são apresentados sistematicamente às formas elementares do trabalho intelectual tendem, como em qualquer outra situação de fracasso escolar, a se perceberem como únicos responsáveis pelas dificuldades que enfrentam. Essa é a forma mais sutil da violência simbólica, porque institucionalizada. E que favorece a manutenção dos valores estruturantes da "excelência universitária", garantindo, pela admiração do que é quase inalcançável, investimentos consideráveis por parte dos estudantes e sua submissão às demandas da cultura legítima. 


\section{A rejeição ao universalismo universitário}

[estudantes de letras] podem até mesmo, se são de origem pequenoburguesa ou popular, experimentar a irrealidade de um professor desatualizado nos seus métodos e às vezes no seu conteúdo, porque está pouco adaptado às expectativas e aos interesses de seu meio ou talvez porque o comparem a um futuro profissional com o qual tenham uma preocupação mais realista. (Bourdieu;Passeron, 2014, p.74)

É preciso considerar a faixa etária de boa parte do corpo discente de Guarulhos e sua condição de trabalhadores - os dois elementos importantes da caracterização desse grupo, na falta de dados empíricos que permitam compreender as dimensões propriamente culturais - para compreender alguns dos elementos presentes na greve dos estudantes de 2012. Inicialmente, o movimento foi amplamente apoiado, tendo em vista a evidente precariedade material do campus. No entanto, à medida que a paralisação se estendia, sem resultados visíveis e dando lugar a episódios de violência contra alunos que desejavam o retorno às aulas e contra professores que tentaram lecionar, verificou-se o esvaziamento do campus, comprovado aqui e ali nas redes sociais por apelos para que se participasse do trabalho cotidiano que o movimento de greve demandava. Queixa recorrente quanto ao modo de funcionamento das assembleias estudantis era a sua duração: os alunos que dependiam do transporte público para retornar às suas casas e os que trabalhavam durante o dia relatavam dificuldade para permanecer até o final das mesmas, quando a questão de se o movimento prosseguiria ou não era posta em votação, após os pronunciamentos mais variados sobre a situação e as demandas dos estudantes, particularmente porque não se tratava de um movimento restrito ao campus Guarulhos, mas de mobilizações de estudantes por todo o país nas universidades.

Ainda que a maioria dos estudantes participe somente de muito longe desses debates e se reconheça nele com dificuldade, as ideias políticas ou os valores estéticos que os opõem e pelos quais se opõem nas discussões sem fim obedecem à mesma lógica. A vontade de se distinguir pode encontrar um terreno bastante fértil ao mesmo tempo na ordem política, na ordem filosófica ou na ordem estética (...)

$\mathrm{Na}$ verdade, a busca da diferença supõe o consensus nos limites pelos 
quais se pode jogar o jogo das diferenças e segundo a necessidade de jogá-lo nesses limites. (Bourdieu; Passeron, 2014, p.67)

Os debates do movimento fizeram surgir, nas manifestações públicas dos estudantes, alguns temas recorrentes: um foi o da "universidade popular", em contraposição à "universidade de elite", representada pelos professores mais conservadores, que defendiam valores mais tradicionamente identificados com o ideal universitário. Outro tema foi o das relações do campus com o local em que se encontrava - nesse caso, o desejo dos professores de contar com uma melhor infraestrutura para suas atividades foi identificado, na polarização que se instaurou, como rejeição do bairro periférico e, por extensão, da sua população. Nesse sentido, é emblemático o slogan "universidade na periferia, para a periferia e pela periferia" que foi utilizado nos meses finais do movimento, como contraposição a argumentos que destacavam o cosmopolitismo e a universalidade representados pela instituição. ${ }^{9}$

A negação, pelo movimento estudantil, daquilo que nesse ambiente era considerado de "elite" por contraposição ao "popular" convivia de modo ambíguo com a valorização da cultura legítima de que a Universidade é portadora. A mesma ambiguidade que se revelou na citação a seguir, retirada de uma carta de um morador do bairro que frequentava as aulas da Unifesp informalmente e que foi lida numa das assembleias estudantis, o desejo do que a Universidade pode proporcionar em termos de apropriação da cultura legítima convive com a percepção de que ela não é um lugar para pobres:

Presenciei inúmeras vezes estudantes e professores dizendo colocações do tipo "As CONDIÇÕES que a universidade se encontra aqui", "A TOTAL falta de estrutura","desse jeito não tem como continuar a estudar e trabalhar aqui", a chegar um determinado ponto onde pessoas passem a acreditar que a NOSSA REGIÃO não mereça essa Instituição Escolar, como se não fossemos dignos, capazes ou a "altura" dessa instituição, como se estivessem nos fazendo um favor com a Unifesp aqui (...) ao

\footnotetext{
${ }^{9}$ Não é possível afirmar o alcance do significado da expressão "universidade popular" ou como seu vínculo com a periferia estava sendo compreendido, tendo em vista que a elaboração sobre o tema, na extensa documentação produzida pelos estudantes durante seu movimento, é bastante escassa, aparecendo, na maior parte das vezes, como slogan.
} 
ponto de um dos patéticos, medíocres e desrespeitosos "Guia de Sobrevivência dos Pimentas" vir a convidar os Calouros a entrarem na "Estranha Galáxia em que fica o bairro dos pimentas...",pois, "os seres" de periferia não são "tão perigosos, basta trancar bem a porta e não andar sozinho de noite" onde "moradores do pimentas querem e precisam de cultura" e "Semáforo vermelho nem sempre significa pare para os motoristas GUARULHENSES". (...) você sobreviverá na região, fará tudo o que sua grade curricular exigir, quando for conveniente entrará em contato com os arredores e escolas públicas da região pra vomitar teorias transformando o Pimentas num laboratório de experiências que podem ser bem sucedidas ou não, mas tanto faz, pois para uma parte o Pimentas tem se tornado uma "Las Vegas", fazem o que querem e depois retornam para o conforto do "Lar" (...) Acredito seriamente que a aproximação entre universidade e região é e será de extrema importância, para que possa acontecer uma transformação no Pimentas tanto quanto na universidade, mas enquanto existirem colocações do tipo "ELES, OS OUTROS, A COMUNIDADE", haverá distâncias e diversas formas de violências na criação e reprodução constante de estereótipos e estigmas. CARTA, 2012, s/p.)

Pode-se considerar o quanto a vivência da universidade comporta de violência simbólica para esse grupo de estudantes, de origem popular, que constitui parcela significativa no campus Guarulhos. Visível na rejeição à universalidade (que é o modo como a universidade se concebe) e na identificação de antagonismos entre alunos e professores que espelhariam a luta de classes, está a dificuldade ou impossibilidade de viver a "irrealidade" da formação universitária, fora da objetividade da preparação profissional. Seria preciso pensar o quanto o trabalho de formação na universidade, sendo também um trabalho sobre si mesmo, na medida em que cabe aos alunos produzirem-se "como produtores de cultura ou como utilizadores altamente especializados da mesma" pode dar lugar a crises existenciais. É impossível não se pensar a si próprio com base nas categorias utilizadas na universidade brasileira para falar, por exemplo, da escola pública ou das desigualdades sociais quando se está nesse lugar de desprivilégio. Quais as condições de apropriação dessas análises e quais os efeitos de aprender a pensar-se a si mesmo sem a possibilidade de distanciamento do mundo que, de algum modo, a instituição universitária tradicional (tal como descrita por Bourdieu) permite - é uma questão que tem indícios de resposta nos registros do movimento discente de Guarulhos, mas que deve ser objeto ainda de investigação. 


\section{A relação pedagógica mistificada}

Para fins de análise, Bourdieu e Passeron propõem um tipo ideal - racional de estudante que permite construir um modelo, embora alertem para a complexidade real que o ensino na universidade apresenta. O tipo ideal - racional do estudante diz respeito a uma identidade transitória, uma vez que objetivamente se trata de ir à universidade durante um certo período para obter uma formação profissional especializada. Esse modelo tem como extremos o utilitarismo e o desinteresse: a "besta dos concursos" preocupado exclusivamente com o desempenho e o "diletante", despreocupado de tudo que não sejam seus interesses de conhecimento. Equivalentes a isso nesta análise são os estudantes que prolongam uma relação "escolar" com as notas e a competitividade que isso enseja, contrapondo-se aos que, entre aqueles que desejam uma segunda graduação, têm o ecletismo do "estudante eterno". Ambas as posições são desvalorizadas no meio universitário, mas só são possíveis por corresponderem a uma cultura institucional que transforma a vida estudantil num fim em si mesmo. Essa autonomização corresponde à vivência do desinteresse que é fundante dos valores universitários mais tradicionais e elevados, e é por essa razão que a universidade se nega como escola, ou melhor, como lugar em que o "escolar" possa ter alguma função.

A autonomização de um estado essencialmente provisório e transitório permite ao estudante esquecer-se como tal esquecendo seu futuro. Assim, a tradição universitária lhe propõe dois grandes modelos que, aparentemente contraditórios, são igualmente aprovados, a "besta dos concursos" e o "diletante". (Bourdieu; Passeron, 2014, p.79)

A experiência mistificada da condição estudantil autoriza a experiência encantada da função professoral: ao estabelecimento da relação, tecnicamente organizada, entre um pedagogo e um aprendiz pode substituir-se o encontro de eleição entre eleitos. ( Bourdieu; Passeron, p.80) 
Na universidade, particularmente na área de humanidades, partilhar da ideologia do dom parece ser uma condição para a entrada na vida intelectual, num modelo de relação entre orientador e orientando que remete às formas do discipulado. A questão é que essas "formas carismáticas tradicionais do ensino", no nível da graduação, e num momento de democratização do ensino superior, possuem efeitos perversos para os estudantes mais desprovidos de capital cultural. Isso porque um ensino baseado na ideologia do dom deixa de ensinar explicitamente as técnicas intelectuais mais básicas que subjazem às grandes obras. Apresentados a uma tradição intelectual que celebra o brilhantismo dos grandes teóricos e pesquisadores, os estudantes pobres (porque se trata disso) não podem nunca se sentir parte desse mundo, a menos que sejam “predestinados” a tanto, por sua excepcionalidade. Aos “medíocres”, resta a sensação de impotência e a dependência da leitura autorizada dos professores. A análise d'Os Herdeiros indica elementos que podem fundamentar uma discussão racional do ensino na universidade - adverte-se, ali, contra a polarização: é possível transitar entre a criação pura e a passividade total dos alunos; entre os elementos do ensino racionalizado e os da tradição universitária ("as formas carismáticas tradicionais do ensino").

Forçados a um projeto profissional mais realista, os estudantes originários das classes baixas nunca podem abandonar-se completamente ao diletantismo ou prender-se aos prestígios ocasionais de estudos que, para eles, permanecem uma oportunidade, que deve ser apreendida, de se elevar na hierarquia social. (Bourdieu ;Passeron, 2014, p. 85)

A ideia central neste artigo é que as condições institucionais e políticas não constituíram os únicos elementos da crise vivida no campus Guarulhos da UNIFESP. A meu ver, o aspecto cultural, identificado como o choque entre os modos tradicionais de funcionamento da universidade e esse público desprovido de capital cultural que a ela tem chegado, tem resultado em situações de violência simbólica às quais os estudantes têm reagido - tanto dentro como fora dos canais institucionais. Essa reação, que desconhece o ethos acadêmico e suas tradições, desprovida do "sentido do jogo" próprio 
da universidade, irrompeu violentamente no caso de Guarulhos, como parte de um processo de formação de um novo modelo de ensino superior, que não pode mais ser o do ensino universitário tradicional, mas ainda não encontrou seu formato.

\section{Referências}

BATISTA, Antonio Augusto; RIBEIRO, Vera Masagão. Cultura escrita no Brasil: modos e condições de inserção. Educação e Realidade, Porto Alegre, v. 29, n. 2, p. 89-124. 2005.

BERTOLUCI, Kaluana. Letramento acadêmico: leitura(s) em um curso de Pedagogia. Revista ao Pé da Letra, v 11.2, 200, p. 105-124. Disponível em: http://www.revistaaopedaletra.net/index.html.

BOURDIEU, Pierre; PASSERON, Jean-Claude Os herdeiros: os estudantes e a cultura. Florianópolis: Ed. da UFSC, 2014.

CARTA de um morador do Bairro dos Pimentas à Unifesp, 27 de março de 2012. In: Arquivo de Greve UNISFESP [internet]. Guarulhos: UNIFESP, 2012. Disponível em:

<http://arquivogreveunifesp.wordpress.com/2012/04/13/carta-de-um-morador-do-bairrodos-pimentas-a-unifesp >. Acesso em: 20/07/2014

CRUZ, Fernanda M.; CESPEDES, Juliana G. O perfil sócio-econômico e cultural dos estudantes da Universidade Federal de São Paulo. Guarulhos: UNIFESP. Pró Reitoria de Assuntos Estudantis, 2012. Disponível em: <http://prae.unifesp.br/arquivosdocumentos/file/86-estudo-do-perfil-socioeconomico-e-cultural-dos-estudantes-daunifesp-ingressantes-2011. Acesso em: 10/07/2014.

UNIFESP em Luta: Blog do Movimento Estudantil [internet]. Guarulhos, 2014. Blog dos estudantes de Guarulhos durante a greve de 2012. Disponível em:

<http://greveunifesp.files.wordpress.com>. Acesso em: 15/07/2014

UNIVERSIDADE FEDERAL DE SÃO PAULO. Acervo documental sobre greves da Unifesp [internet]. Disponível em: <https://arquivogreveunifesp.wordpress.com>. Acesso em: 20/07/2014. 
UNIVERSIDADE FEDERAL DE SÃO PAULO. Escola de Filosofia, Letras e Ciências Humanas. Dossiê para debate: a crise da Escola de Humanidades da Unifesp e sua permanência nos Pimentas. Guarulhos: UNIFESP, 2012. Disponível em:

<http://greveunifesp.files.wordpress.com/2012/08/dossie-sobre-a-crise-da-eflch-unifesp-eo-bairro-dos-pimentas1.pdf>. Acesso em: 20/07/2014

ZAGO, Nadir. Prolongamento da escolarização nos meios populares e as novas formas de desigualdades educacionais. In: PAIXÃO, Léa Pinheiro e ZAGO, Nadir (org.) Sociologia da educação: pesquisa da realidade brasileira.

Recebido em: 06/10/2013

Aprovado em: 18/02/2014

Universidade do Estado de Santa Catarina - UDESC

Programa de Pós-Graduação em Educação - PPGE

Revista Linhas

Volume 15 - Número 29 - Ano 2014

revistalinhas@gmail.com 